https://helda.helsinki.fi

\title{
Hanging suicides in northern Finland : A descriptive epidemiological study
}

Kanamuller, Juha

2016

Kanamuller , J, Riipinen , P , Riala , K, Paloneva , E \& Hakko , H 2016 , ' Hanging suicides in northern Finland: A descriptive epidemiological study ' , Death Studies , vol. 40 , no. 4 , pp. 205-210 . https://doi.org/10.1080/07481187.2015.1117537

http://hdl.handle.net/10138/161429

https://doi.org/10.1080/07481187.2015.1117537

publishedVersion

Downloaded from Helda, University of Helsinki institutional repository.

This is an electronic reprint of the original article.

This reprint may differ from the original in pagination and typographic detail.

Please cite the original version. 


\title{
Hanging suicides in northern Finland: A descriptive epidemiological study
}

\author{
Juha Kanamüller, Pirkko Riipinen, Kaisa Riala, Eero Paloneva \& Helinä Hakko
}

To cite this article: Juha Kanamüller, Pirkko Riipinen, Kaisa Riala, Eero Paloneva \& Helinä Hakko (2016) Hanging suicides in northern Finland: A descriptive epidemiological study, Death Studies, 40:4, 205-210, DOI: 10.1080/07481187.2015.1117537

To link to this article: http://dx.doi.org/10.1080/07481187.2015.1117537

Dec 2015.

Published online: 17 Dec 2015.

Submit your article to this journal $\sqsubset$

Џll Article views: 54

Q View related articles 5

View Crossmark data $־$ 


\title{
Hanging suicides in northern Finland: A descriptive epidemiological study
}

\author{
Juha Kanamüller ${ }^{a}$, Pirkko Riipinen ${ }^{b}$, Kaisa Riala ${ }^{a, c}$, Eero Paloneva ${ }^{a}$, and Helinä Hakko

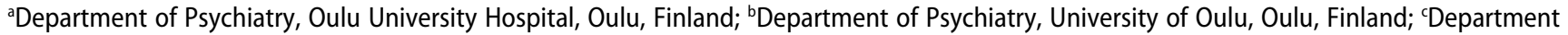 \\ of Adolescent Psychiatry, Helsinki University Central Hospital, Helsinki, Finland
}

\begin{abstract}
The authors examined all hanging-suicides during 1988-2013 $(N=851)$ in the province of Oulu, northern Finland. Using death-certificate data and ICD-diagnoses from the Finnish Hospital Discharge Register, we focused on gender differences in suicide, mental health, and somatic health. Male victims were more likely to have intoxication or problematic alcohol use; female victims were more likely to have somatic or mental hospitalization. Previous physical or mental hospitalization was related with absence of intoxication at the time of suicide. Suicide prevention should focus on acute alcohol abuse in the presence of acute stressors, suicidal thoughts and mental illness.
\end{abstract}

Suicide rates have been increasing globally since 1950 (World Health Organization, 2014). In Finland the absolute number of suicides continued to increase from the year 1920 with a peak in 1990. The rate has declined since 1990 , but nearly 1,000 suicides still occur every year (Statistics Finland, 2014). In an analysis of suicide methods in 16 European countries, hanging was the most commonly used method both in both sexes (Värnik et al., 2008). Hanging seems to be the method of choice worldwide, except for in countries with easy access to firearms (Ajdacic-Gross et al., 2008). In Finland between 2000 and 2005, 33\% of male and $21 \%$ of female suicide victims died by hanging, making it the most common suicide method for men and the second most common for women, after poisoning (Värnik et al., 2008). The choice of hanging as a suicide method may be influenced by practical and psychological factors, such as easy access to the means of hanging, its perceived lethality, an anticipated quick and relatively painless death, the absence of blood, and its ease (Biddle et al., 2010).

With regard to suicide prevention, hanging represents a particularly problematic method of suicide. A systematic review (Gunnel, Bennewith, Hawton, Simkin, \& Kapur, 2005) and a qualitative study (Biddle et al., 2010) have emphasized that prevention efforts can restrict access to many other means of suicide, such as firearms or drugs, but restriction is not possible in the case of hanging. Therefore, prevention strategies for the general population have to focus on awareness-raising, primary-preventive services, educational programs, and more general measures such as improving living conditions. Such an approach may fail to target the relevant individuals at their time of crisis.

Different populations choose different methods when committing suicide. In Finland, for example, men primarily commit suicide by hanging, whereas women primarily commit suicide by poisoning (Värnik et al., 2008). It would be useful to know more about those individuals who choose hanging as their suicide method, particularly with regard to potential gender differences. For this purpose we analyzed gender differences in hanging suicides, specifically their acute and previous use of alcohol and other substances, adverse life events, suicide ideation and attempt history, mental and physical health history, and place and timing of suicide.

\section{Method}

\section{Sample}

The study population consisted of $719(84 \%)$ boys/men and $132(15 \%)$ girls/women who committed suicide by hanging between 1988 and 2013 in the province of Oulu in northern Finland. The youngest person was 12 years old; the oldest was 90 . The mean age at suicide death by hanging was $46.2(S D=16.5)$ years. The province of Oulu is inhabited by 479,815 people ( $8.9 \%$ of the Finnish population) with a population density of 8.4 persons/ $\mathrm{km}^{2}$ (17.8 persons $/ \mathrm{km}^{2}$ in whole country). The unemployment rate is $11.2 \%$ (9.4\% in the whole country) and $69.6 \%(72.9 \%)$ of working-age population is 
employed in services, $23.1 \%(22.1 \%)$ in industry, and $5.8 \%(3.7 \%)$ in agriculture, forestry, hunting, and fishing (Statistics Finland, 2012).

\section{Data sources}

\section{Death certificates}

Under Finish law, police investigate unexpected, sudden, and unnatural deaths for the possibility of suicide, a process that requires a medical examination. The forensic examiner then decides whether or not to classify a death as suicide. Our basic data came from these official death certificates. The death certificates contain date of birth, the method of suicide, date and location where the victim's body was found, and any related medical diagnoses, for example, if the victim was under the influence of alcohol at the time of death. The death certificates also contain a blank space for additional free text comments, usually used for information that might be of any relevance to the suicide, such as previous suicide threats, substance use, or adverse life events before the suicide.

\section{Finnish hospital discharge register}

Researchers obtained physical and psychiatric diagnoses associated with the deceased person's hospital treatments from the Finnish Hospital Discharge Register (FHDR). The FHDR covers all lifetime treatment in general, mental, prison, and military hospitals, and in the inpatient wards of local health centres throughout Finland.

\section{Measures}

Information on acute alcohol and substance intoxication (yes/no) at the time of death was based on the results of forensic post-mortem examinations. The free text field on death certificates was used to gather information about any problems (yes/no or unknown) experienced by victim prior to their suicide. Such information included alcohol use (alcoholism, high use of alcohol, or alcohol problem), adverse life events (physical illness, relationship problems, argument with a close person, bereavement, financial problems or unemployment, and legal problems), talk of committing suicide, previous suicide attempt(s), location of suicide (home, home yard/ garden, outdoors, other private building, prison/holding cell/police car, and hospital), and timing of suicide.

\section{Results}

Table 1 summarizes the results of gender differences in acute and previous use of alcohol and other substances. Male victims were more often intoxicated at the time of
Table 1. Acute and previous use of alcohol and other substances among hanging suicide victims by sex.

\begin{tabular}{|c|c|c|c|c|}
\hline \multirow{2}{*}{$\begin{array}{l}\text { ICD classification } \\
\text { of diseases }\end{array}$} & \multirow[b]{2}{*}{ Total $^{a}$} & \multicolumn{2}{|c|}{ Gender } & \multirow{2}{*}{$\begin{array}{c}p- \\
\text { value }\end{array}$} \\
\hline & & Men & Women & \\
\hline $\begin{array}{l}\text { Intoxicated at the time } \\
\text { of death }^{b}\end{array}$ & $325(38 \%)$ & $287(40 \%)$ & $38(29 \%)$ & .016 \\
\hline Alcohol & $311(36 \%)$ & $276(38 \%)$ & $35(26 \%)$ & .009 \\
\hline Other substances & $30(3 \%)$ & $21(3 \%)$ & $9(7 \%)$ & .037 \\
\hline Problematic alcohol use $e^{b}$ & $147(18 \%)$ & $133(18 \%)$ & $14(11 \%)$ & .027 \\
\hline $\begin{array}{l}\text { Inpatient hospitalizations } \\
\text { due to alcohol- and } \\
\text { substance-related disorders }\end{array}$ & $170(20 \%)$ & $156(22 \%)$ & $14(11 \%)$ & .003 \\
\hline Alcohol-related & $166(19 \%)$ & $153(21 \%)$ & $13(10 \%)$ & .002 \\
\hline
\end{tabular}

${ }^{a}$ Percent of $N$.

${ }^{b}$ Information based on the death certificate.

${ }^{c}$ Information from the Finnish Hospital Discharge Registers (FHDR).

death compared to female victims ( $40 \%$ vs. $29 \%), \chi^{2}(1$, $N=851)=5.85, p=.016$; more often intoxicated with alcohol $(38 \%$ vs. $26 \%), \chi^{2}(1, N=851)=6.78, p=.009$, but less often intoxicated with other substances $(3 \%$ vs. $7 \%), \chi^{2}(1, N=851)=4.98, p=.037$. Male victims also had more problematic alcohol use $(18 \%$ vs. $11 \%), \chi^{2}(1, N=851)=4.86, p=.027$, more hospitalizations for substance-related disorders $(22 \%$ vs. $11 \%)$, $\chi^{22}(1, N=851)=8.58, p=.003$, and more hospitalizations for alcohol-related disorders $(21 \%$ vs. $10 \%), \chi^{2}(1$, $N=851)=9.28, p=.002$.

In contrast, female victims had more physical illnesses $(23 \%$ vs. $15 \%), \chi^{2}(1, N=851)=5.41, p=.02$. For male victims, physical illness was associated with not being intoxicated at the time of hanging suicide $(31 \%$ of intoxicated vs. $42 \%$ of not intoxicated), $\chi^{2}(1, n=719)$ $=4.39, p=.036$. For female victims, the numbers were not sufficient to make comparisons.

A significantly greater proportion of female than male victims who died by suicide had previously attempted suicide $(30 \%$ vs. $8 \%), \chi^{2}(1, N=851)=50.76 ; p<$ .001 . Twenty-one percent of all hanging suicide victims had previously talked about suicide, the proportions being equal in male and female victims $(21 \%$ vs. $20 \%), \chi^{2}(1, N=851)=0.02, p=.887$, as was the proportion of suicide notes left before suicide (12\% vs. $11 \%), \chi^{2}(1, N=851)=0.16 ; p=.689$.

Of all hanging suicide victims, $43 \%$ had a history of hospital-treated mental disorders, female victims significantly more often than male victims ( $51 \%$ of women vs. $41 \%$ of men $), \chi^{2}(1, N=851)=4.74, p=.029$. Suicide victims with hospital-treated mental disorders were less frequently intoxicated at the time of suicide both in male ( $34 \%$ of hospitalized vs. $44 \%$ of not hospitalized), $\chi^{2}(1$, $N=719)=6.55, p=.010$, and in female victims $(15 \%$ of hospitalized vs. $44 \%$ of not hospitalized), $\chi^{2}(1, N=132)$ $=13.57, p<.001$. In victims with a history of mental disorders, male victims were more commonly intoxicated at the time of death than female victims ( $34 \%$ of men/boys 
vs. $15 \%$ of women/girls $), \chi^{2}(1, N=365)=10.03$, $p=.002$. Of specific hospital-treated mental disorders, female victims had a higher prevalence of psychotic ( $16 \%$ in women/girls vs. $10 \%$ in men/boys), $\chi^{2}(1, N=$ $851)=3.98, p=.046$, and mood disorders $(31 \%$ in women/girls vs. $16 \%$ in men/boys), $\chi^{2}(1, N=851)=$ $16.52, p<.001$. No gender difference was found in neurotic disorders $(17 \%$ in women/girls vs. $12 \%$ in men/boys).

Suicide victims with a history of any hospital-treated physical illnesses, where information was obtained from the hospital discharge registers, did not differ statistically significantly between genders $(74 \%$ of men/boys vs. $75 \%$ of women/girls). When gender differences were examined in major categories of hospital-treated physical illnesses, however, statistically significant differences were identified (see Table 2 for overview). A greater proportion of female victims had been treated for neoplasms $(12 \%$ vs. $\left.6 \%), \chi^{2}(1, N=851)=7.80, p=.005\right)$; endocrine, nutritional, and metabolic diseases ( $8 \%$ vs. $4 \%$ ), $\chi^{2}(1, N=851)=6.00, p=.015$; genitourinary diseases $(26 \%$ vs. $9 \%), \chi^{2}(1, N=851)=33.66, p<.001$; and factors influencing health status and need for contact with health services ( $9 \%$ vs. $4 \%), \chi^{2}(1, N=851)=7.83, p=$ .005 , compared to male victims. Male victims had been treated significantly more frequently for respiratory diseases $(29 \%$ vs. $12 \%), \chi^{2}(1, N=851)=16.92, p<.001$.

For the location of suicide, male victims more commonly committed suicide somewhere in their own garden or yard $(25 \%$ vs. $11 \%), \chi^{2}(1, N=851)=$ $11.41, p=.001$, female victims more commonly hung themselves in their home ( $65 \%$ vs. $51 \%), \chi^{2}(1, N=851)$ $=9.54, p=.002$, or in hospital $(7 \%$ vs. $3 \%), \chi^{2}(1$, $N=851)=6.11, p=.020$.

A significant gender difference existed in the choice of weekday for hanging suicide, $\chi^{2}(1, N=851)=20.61, p=$ .002 , as shown in Figure 1. Only $13 \%$ of male hanging suicides occurred on Mondays compared to $26 \%$ of female hanging suicides, $X^{2}(1, N=851)=14.86$,

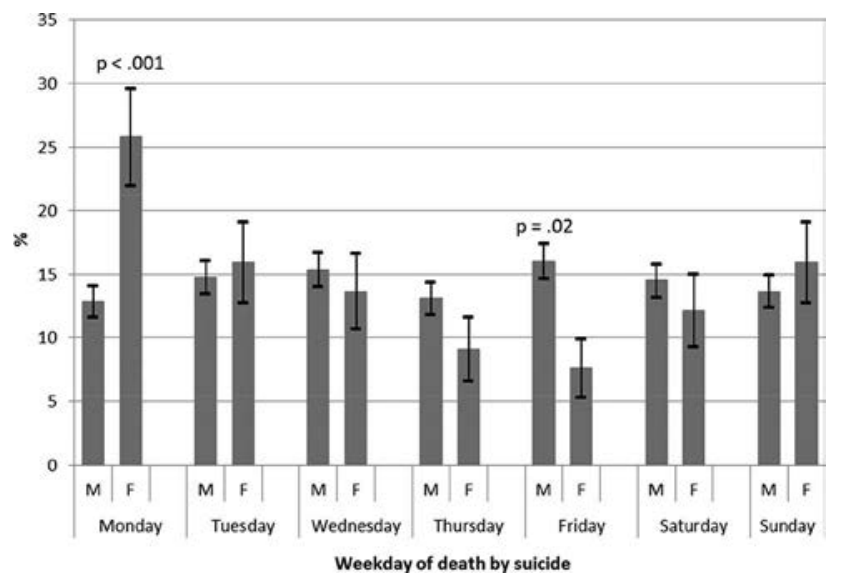

Figure 1. Weekday distribution of hanging suicides by gender.

$p<.001$. Conversely, $16 \%$ of the male victims committed suicide on Fridays compared to $8 \%$ of female victims, $\chi^{2}(1, N=851)=6.31, p=.012$.

\section{Discussion}

We analyzed all cases of hanging suicides occurring during a 25-year period in a northern region of Finland, linking death information with information about previous mental and somatic health hospital treatment obtained from the Finnish Hospital Discharge register. Compared to their female counterparts, male victims were significantly more frequently intoxicated at their time of death; more likely to have a history of problematic alcohol use, and hospitalizations for respiratory diseases; and they usually committed suicide outside their home and on a Friday ( $25 \%$ chance). Female victims, in contrast, more often had a history of schizophrenia, schizotypal, delusional, and mood disorders; hospital treatments due to neoplasms, endocrine, nutritional, and metabolic diseases; diseases of the genitourinary system, co-morbid physical illnesses, and other factors influencing health status and contact with health services; a history of previous suicide attempts; and they

Table 2. Hospital-treated physical illnesses of hanging suicide victim by sex.

\begin{tabular}{|c|c|c|c|c|}
\hline ICD classification of diseases & Total & Male suicide victims & Female suicide victims & $p$-value \\
\hline Infectious and parasitic diseases & $80(9 \%)$ & $72(10 \%)$ & $8(6 \%)$ & .153 \\
\hline Neoplasms & $56(7 \%)$ & $40(6 \%)$ & $16(12 \%)$ & .005 \\
\hline Endocrine, nutritional and metabolic diseases & $37(4 \%)$ & $26(4 \%)$ & $11(8 \%)$ & .015 \\
\hline Diseases of the nervous system & $72(8 \%)$ & $59(8 \%)$ & $13(10 \%)$ & .533 \\
\hline Diseases of the circulatory system & $179(21 \%)$ & $149(21 \%)$ & $30(23 \%)$ & .604 \\
\hline Diseases of the respiratory system & $227(27 \%)$ & $211(29 \%)$ & $16(12 \%)$ & $<.001$ \\
\hline Diseases of the digestive system & $198(23 \%)$ & $170(24 \%)$ & $28(21 \%)$ & .543 \\
\hline Diseases of the musculoskeletal system and connective tissue & $158(19 \%)$ & $127(18 \%)$ & $31(23 \%)$ & .114 \\
\hline Diseases of the genitourinary system & $99(12 \%)$ & $64(9 \%)$ & $35(26 \%)$ & $<.001$ \\
\hline $\begin{array}{l}\text { Symptoms, signs and abnormal clinical and laboratory findings, } \\
\text { not elsewhere classified }\end{array}$ & $199(23 \%)$ & $168(23 \%)$ & $31(23 \%)$ & .976 \\
\hline Injury, poisoning and other consequences of external causes & $354(42 \%)$ & $297(41 \%)$ & $57(43 \%)$ & 688 \\
\hline External causes of morbidity and mortality & $276(32 \%)$ & $233(32 \%)$ & $43(33 \%)$ & .969 \\
\hline Factors influencing health status and contact with health services & $38(4 \%)$ & $26(4 \%)$ & $12(9 \%)$ & .005 \\
\hline
\end{tabular}

Note. Information extracted from the Finnish Hospital Discharge Registers (FHDR). 
more commonly committed suicide on a Monday. Hospitalization for psychiatric or somatic reasons was negatively associated with being intoxicated at the time of suicide.

Alcohol played a significant role in the hanging suicides in our study. Male victims were more frequently intoxicated by alcohol at their time of suicide than female victims who, conversely, were more commonly under the influence of other substances than male victims. A large nationwide U.S. sample of adult suicide victims reported similar results of alcohol intoxication in suicides by hanging, firearm, and poisoning suicides among both sexes (Conner, Bagge, Goldston, \& Ilgen, 2014a). A study with 293 suicide cases from Western Australia (1986-1988) reported higher global alcohol intoxication rates for suicides in general, with men more likely to be intoxicated with alcohol than women (Hayward, Zubrick, \& Silburn, 1992). Recent gender-specific analysis from the National Violent Death Reporting System reported that both men and women who used a violent method of suicide, such as firearms and hanging, were more likely to be intoxicated at the time of death, men significantly more commonly than women (Kaplan et al., 2013b). It is well-acknowledged that the effect of alcohol intoxication may lead to interpersonal conflicts, poor judgment and self-control, a tendency to take risks, increase aggression toward the self and can induce cognitive constriction and impulsive behavior (Hufford, 2001; Kaplan et al., 2013a; Conner et al., 2014b). Alcohol may also serve as "liquid courage" to complete suicide intentions or to anesthetize anticipated pain (Bagge \& Sher, 2008). Present suicide by hanging victims in northern Finland resembled those in other countries in that using alcohol is a high-risk factor.

Our study showed that the location of hanging suicide was most likely to be the victim's home or a location nearby. Interestingly, female victims were more likely to choose the inside of their homes as the place to commit suicide; boys/men preferred their home yards, gardens, or outbuildings. Among 719 suicide victims over a 3-year period from Riverside County, California, over a half took place at the victim's home (Kposowa \& McElvain, 2006). A possible explanation for choosing home to commit suicide might be the media, especially in popular movies, where men who hang themselves use strong and high ligature points like crossbeams. Experts emphasize the importance of working with the media to reduce the portrayal of fictional suicides by hanging and news reporting of hanging suicides (Gunnel et al., 2005). Other explanations for choosing to commit suicide at home might be the likelihood of being found (Beghi, Rosenbaum, Cerri, \& Cornaggia, 2013).

In our data, female hanging suicide deaths were more common on Mondays, but male suicide deaths were more common on Fridays. Research findings on this topic are inconsistent. For example, a German study using suicide data from the state of Lower Saxony, in the former West-Germany from 1968 to 1977, reported a general and a hanging suicide peak on Mondays for both men and women (Massing \& Angermeyer, 1985). A U.S. study found a Wednesday peak for all suicides for both sexes (Kposowa \& D'Auria, 2010). The Monday peak might be partially explained by increased mental distress associated with the stresses of everyday life and work at the start of a new week. In women in particular, stress levels are shown to be higher on working days than weekends (Kunz-Ebrecht, Kirschbaum, \& Steptoe, 2004). The Friday peak in hanging suicide of male victims may relate to increased use of alcohol towards the weekend (Mäkelä, Tigersted, \& Mustonen, 2012).

Over $40 \%$ of male and about half of female hanging suicide victims had a diagnosis for hospital-treated mental disorder. In comparison, a large-scale case-control study from Denmark using national registers comparable to those of our study, $37 \%$ of men and $57 \%$ of women who committed suicide had a history of admission to psychiatric hospitals (Qin \& Nordentoft, 2005). In our data, female victims were overrepresented in schizophrenia, schizotypal and delusional disorders, and mood disorders, which likewise concur with the women/girls preponderance in the abovementioned Danish study. In the Danish study $7 \%$ of male and $9 \%$ of female suicide victims had a diagnosis of schizophrenia spectrum disorders compared with $10 \%$ in men and $15 \%$ of women observed in our study. For affective disorders, they reported an incidence of $9 \%$ in male and $19 \%$ in female suicides compared with $16 \%$ of men/ boys and $31 \%$ of women/girls in our data. Thus, the present data is similar to Danish data, with perhaps a slightly higher rate of schizophrenia spectrum and affective disorder in Finnish suicide by hanging victims.

Physical illness, as recorded on death certificates, was found in every sixth suicide victim, with higher rates among female than male victims, but those with physical illnesses were less likely to be intoxicated at the time of suicide. On the other hand, one fifth to one fourth of all victims had been treated in hospital inpatient care for diseases of the circulatory, respiratory, or digestive system. Female victims were more likely to have been treated for neoplasms, endocrine, nutritional and metabolic diseases, diseases of the genitourinary system, and "other factors influencing health status and contact with health services," whereas male victims were more likely to be treated for respiratory diseases. Our findings are in line with previous studies. Persons with physical illness, particularly those with psychiatric comorbidity, are shown to be at increased risk for suicide (Qin, 
Hawton, Mortensen, \& Webb, 2014). In Alberta, Canada, for example, in deaths of people over age 55, higher rates of somatic diseases were found in suicide victims than in motor vehicle accident death victims (Quan, Arboleda-Flórez, Fick, Stuart, \& Love, 2002).

In our data, a fifth of all victims had expressed suicide intentions prior to their death and about every tenth of the victims had previous suicide attempts, women more commonly than men. Interviews with over 84,850 adults in 17 countries revealed that, within 1 year of the onset of suicidal ideation, people are at a highly elevated risk for planning or attempting suicide (Nock et al., 2008).

A major strength of our descriptive epidemiological study is a large database containing all suicides by hanging occurring in the province of Oulu from 1988 to 2013, and reliable data based on death certificates from forensic medical-legal investigations. On an individual level, we were able to link data from the FHDR to the death certificate data. The FHDR data covers information on all treatments in all hospitals in Finland as well as treatments in inpatient wards in local health centers. We could, therefore, link indications for previous psychiatric and somatic hospital inpatient treatments to hanging suicides. Unfortunately, this also means that only those conditions deemed severe enough for hospitalization are included in our data, because data were not available on treatments in outpatient settings.

A limitation of our study is that information on adverse life events, alcohol abuse, suicide notes, suicidal ideation and previous suicide attempts was based on death certificates written by medical examiners. Therefore, it is likely that these variables are underestimates. Data from psychological autopsy investigations would have provided us with a deeper understanding of the clinical state of the hanging suicide victims. It also remains an open question as to why hanging has remained such a popular method of suicide. In addition, the likelihood for chance findings (Type I error) cannot be excluded due to the many statistical comparisons performed in our study. Conversely, the small number of cases in some subgroup comparisons may have caused a lack of statistical power (Type II error).

Studies focusing on hanging suicides are still rare and, accordingly, our study represents an important addition to the existing literature. Hanging is a method of suicide that cannot be prevented by restricting the availability of means, as is done in firearm suicide by restricting the access to firearms or in poisoning suicides by prescribing safer medication. With regard to suicide prevention the role of acute alcohol use cannot be stressed enough. Also, risk factors associated with acute or chronic use of alcohol should form an essential focus within suicide prevention programmes.

\section{References}

Ajdacic-Gross, V., Weiss, M. G., Ring, M., Hepp, U., Bopp, M., Gutzwiller, F., \& Rössler, W. (2008). Methods of suicide: International suicide patterns derived from the WHO mortality database. Bulletin of the World Health Organization, 86, 726-732. doi:10.2471/blt.07.043489

Bagge, C. L., \& Sher, K. J. (2008). Adolescent alcohol involvement and suicide attempts: Toward the development of a conceptual framework. Clinical Psychology Review, 28, 1283-1296. doi:10.1016/j.cpr.2008.06.002

Beghi, M, Rosenbaum, J. F., Cerri, C., \& Cornaggia, C. M. (2013). Risk factors for fatal and nonfatal repetition of suicide attempts: A literature review. Neuropsychiatric Disease and Treatment, 9, 1725-1736. doi:10.2147/NDT.S40213

Biddle, L., Donovan, J., Qwen-Smith, A., Potokar, J., Longson, D., Hawton, K., ... Gunnel, D. (2010). Factors influencing the decision to use hanging as a method of suicide: Qualitative study. The British Journal of Psychiatry, 197, 320-325. doi:10.1192/bjp.bp.109.076349

Conner, K. R., Bagge, C. L., Goldston, D. B., \& Ilgen, M. A. (2014a). Alcohol and suicidal behavior: What is known and what can be done. American Journal of Preventive Medicine, 47(2), 204-208.

Conner, K. R., Huguet, N., Caetano, R., Giesbrecht, N., McFarland, B. H., Nolte, K. B., \& Kaplan, M. S. (2014b). Acute use of alcohol and methods of suicide in a US national sample. American Journal of Public Health, 104 (1), 170-178. doi:10.2105/AJPH.2013.301352

Gunnel, D., Bennewith, O., Hawton, K., Simkin, S., \& Kapur, N. (2005). The epidemiology and prevention of suicide by hanging: A systematic review. International Journal of Epidemiology, 34, 433-442. doi:10.1093/ije/dyh398

Hayward, L., Zubrick, S. R., \& Silburn, S. (1992). Blood alcohol levels in suicide cases. Journal of Epidemiology and Community Health, 46, 256-260. doi:10.1136/jech.46.3.256

Hufford, M. R. (2001). Alcohol and suicidal behavior. Clinical Psychology Review, 21(5), 797-811. doi:10.1016/S0272-7358 (00)00070-2

Kaplan, M. S., Giesbrecht N., Caetano, R., Conner, K. R., Huguet, N., McFarland, B. H., \& Nolte, K. B. (2013a). Acute alcohol consumption as a contributing factor to suicidal behavior. American Journal of Public Health, 9, e2-e3. doi:10.2105/AJPH.2013.301422

Kaplan, M. S., McFarland, B. H., Huguet, N., Conner, K., Caetano, R., Giesbrecht, N., \& Nolte, K. B. (2013b). Acute alcohol intoxication and suicide: a gender-stratified analysis of the national violent death reporting system. Injury Prevention, 19, 38-43. doi:10.1136/injuryprev-2012-040317

Kposowa, A. J., \& D'Auria, S. (2010). Association of temporal factors and suicides in the United States, 2000-2004. Social Psychiatry and Psychiatric Epidemiology, 45, 433-445. doi:10.1007/s00127-009-0082-9

Kposowa, A. J., \& McElvain, J. P. (2006). Gender, place, and method of suicide. Social Psychiatry and Psychiatric Epidemiology, 41, 435-443. doi:10.1007/s00127-006-0054-2

Kunz-Ebrecht, S. R., Kirschbaum, C., \& Steptoe, A. (2004). Work stress, socioeconomic status and neuroendocrine 
activation over the working day. Social Science and Medicine, 58(8), 1523-1530. doi:10.1016/S0277-9536(03) 00347-2

Massing, W., \& Angermeyer, M. C. (1985). The monthly and weekly distribution of suicide. Social Science \& Medicine, 21 (4), 433-441. doi:10.1016/0277-9536(85)90223-0

Mäkelä, P., Tigersted, C., \& Mustonen, H. (2012). The Finnish drinking culture: Change and continuity in the past 40 years. Drug and Alcohol Review, 31, 831-840. doi:10.1111/ j.1465-3362.2012.00479.x

Nock, M. K., Borges, G., Bromet, E. J., Alonso, J., Angermeyer, M., Beautrais, A., ... Williams, D. R. (2008). Cross-national prevalence and risk factors for suicidal ideation, plans, and attempts. British Journal of Psychiatry, 192, 98-105. doi:10.1192/bjp.bp.107.040113

Qin, P., Hawton, K., Mortensen, P. B., \& Webb, R. (2014). Combined effects of physical illness and comorbid psychiatric disorder on risks of suicide in a national population study. British Journal of Psychiatry, 204, 430-435. doi:10.1192/bjp.bp.113.128785

Qin, P., \& Nordentoft, M. (2005). Suicide risk in relation to psychiatric hospitalization. Evidence based on longitudinal registers. Archives of General Psychiatry, 62, 427-432. doi:10.1001/archpsyc.62.4.427

Quan, H., Arboleda-Flórez, J., Fick, G. H., Stuart, H. L., \& Love, E. J. (2002). Association between physical illness and suicide among the elderly. Social Psychiatry and Psychiatric Epidemiology, 37, 190-197. doi:10.1007/s001270200014

Statistics Finland. (2012). Statistical yearbook of Finland 2012. Retrieved from http://pxweb2.stat.fi/sahkoiset_julkaisut/ vuosikirja2012/pdf/julkaisu.pdf

Statistics Finland. (2014). Statistical database, health/causes of death. Retrieved from http://pxweb2.stat.fi/database/ StatFin/databasetree_en.asp (February 28, 2014).

Värnik, A., Kolves, K., van der Feltz-Cornelis, C. M., Marusic, A., Oskarsson, H., Palmer, A.,... Hegerl, U. (2008). Suicide methods in Europe: A gender-specific analysis of countries participating in the "European Alliance Against Depression". Journal of Epidemiology \& Community Health, 62, 545-555. doi:10.1136/jech.2007.065391

World Health Organization. (2014). Mental health: Evolution 1950-2000 of global suicide rates (pre 100'000). Retrieved from http://www.who.int/mental_health/prevention/ suicide/evolution/en/index.html (March 31, 2014). 